\title{
UM OLHAR DA AVALIATIVIDADE PARA A CONSTRUÇÃO DE CRENÇAS DE UM GRUPO DE ALUNOS SOBRE O PROFESSOR DE INGLÊS
}

\author{
AN APPRAISAL ANALYSIS ON BELIEFS OF A GROUP OF \\ STUDENTS ABOUT THE ENGLISH TEACHER
}

\author{
Adriana Nogueira Accioly Nóbrega (PUC-Rio) \\ adriananobrega@puc-rio.br \\ Mara Regina de Almeida Griffo (PUC-Rio) \\ marargriffo@gmail.com
}

\begin{abstract}
RESUMO: Neste artigo, analisamos as crenças de alunos, entre 9 e 10 anos, sobre seus entendimentos do que seria um bom professor de inglês no contexto educacional no qual estão inseridos, a saber, o Programa Bilíngue em língua inglesa, de uma escola da rede particular de ensino, localizada em um município do Estado do Rio de Janeiro. Construímos a arquitetura teórica fundamentadas na Linguística Sistêmico-Funcional, em seu sistema de avaliatividade, enfocando a perspectiva social dos estudos de crenças no ensino de línguas. Inspiradas pela pesquisa do praticante, que se alinha ao paradigma qualitativo, duas atividades pedagógicas foram propostas, gerando reflexões sobre o tema. Conversas entre os participantes foram gravadas e transcritas para a sua análise microdiscursiva, quando investigamos os recursos linguísticos avaliativos, bem como a sua correlação com a construção das crenças. Nossos entendimentos sugerem que as crenças emergem de avaliações de afeto e de julgamento e relacionam-se à experiência profissional do professor, ao seu domínio do idioma e à importância do lúdico na formação do aluno.
\end{abstract}

PALAVRAS-CHAVE: linguística sistêmico-funcional; avaliação; crenças no ensinoaprendizagem de língua inglesa.

ABSTRACT: In this article, we analyze the beliefs of students, aged 9 and 10, about their understandings of what a good English teacher should be like in their educational setting: a Bilingual Program in English teaching-learning in a private school, located in a city in the State of Rio de Janeiro. The theoretical architecture is based on the Systemic-Functional Linguistics, on its appraisal theory, with focus on the social aspects of beliefs in language teaching-learning. Inspired by the practitioner research, and aligned with the qualitative paradigm, two pedagogical activities were proposed to motivate reflections on the theme. Conversations between the participants were recorded and transcribed for the micro discursive analysis, when the evaluative linguistic resources were investigated, as well as 
their correlation with the construction of beliefs. Our understandings suggest that the beliefs emerge from evaluations of affect and judgment that related to the teacher's professional experience, their mastery of the language, and the importance of ludic in the student's education.

KEYWORDS: systemic-functional linguistics; evaluation; beliefs in English teachinglearning.

\section{Considerações iniciais}

No contexto pedagógico, uma forma de se fazer pesquisa é por meio do envolvimento dos seus participantes na rotina da sala de aula, bem como da sua reflexão sobre questões do cotidiano inerentes a tal ambiente. Com isso, torna-se possível que os participantes posicionem-se com uma lente de aumento, a fim de observar o que parece ser conhecido e familiar (VELHO, 1978) e, ao mesmo tempo, buscar entender a multiplicidade de aspectos que fazem parte do universo cultural e interacional do cenário escolar onde atuam. Este tipo de pesquisa requer a compreensão de que os posicionamentos e as avaliações que são feitos dos eventos pedagógicos são perspectivados e marcados por visões de alunos e de professores (MILLER et al, 2008; MILLER et al, 2019).

Nesse sentido, é importante reconhecer que tais avaliações se baseiam em crenças e em valores pessoais, que orientam os entendimentos que os participantes constroem das situações sociais nas quais interagem. Como aponta Barcelos (2004, p. 136), "as crenças podem atuar como lentes através das quais os alunos interpretam as novas informações recebidas durante sua formação", sendo esse o ponto que nos motiva a analisar o discurso de três alunos da Mara, segunda autora deste artigo, que cursam o Programa Bilíngue em uma escola da rede particular, localizada em um município do Estado do Rio de Janeiro. Inspiradas pelas palavras da autora, que se voltam à investigação das crenças no processo de formação de professores de línguas, temos como propósito analisar o discurso dos três alunos, crianças entre 9 e 10 anos de idade. Tal investigação ocorre a partir da nossa curiosidade por (re)conhecer quais crenças sobre o ensino-aprendizagem de língua inglesa já encontram-se em formação em seus posicionamentos sobre o tema, em especial do que é "ser um bom professor" dessa área em seu contexto escolar.

Como educadoras, acreditamos que "nós precisamos aprender a trabalhar com crenças em sala, já que ter consciência sobre nossas crenças e ser capaz de falar sobre elas é um 
primeiro passo para professores e alunos reflexivos" (BARCELOS, 2004, p. 145) e, portanto, trazemos os seguintes objetivos para o desenvolvimento desta pesquisa: (i) investigar a construção de crenças dos três alunos participantes; (ii) refletir sobre as crenças acerca do papel do professor sob a ótica dos alunos, (iii) analisar microdiscursivamente as escolhas léxico-gramaticais avaliativas utilizadas pelos alunos; e (iv) observar como os recursos linguísticos avaliativos colaboram para construção de tais crenças.

Para tanto, construímos a arquitetura teórica deste estudo fundamentadas na perspectiva de linguagem sociossemiótica proposta pela Linguística Sistêmico-Funcional (HALLIDAY; MATTHIESSEN, 2014), com foco no Sistema de Avaliatividade, inicialmente idealizado por Martin (2001) e Martin e White (2005), em alinhamento com os estudos de crenças no ensino de línguas (BARCELOS, 2013; PERINE, 2012; ARAGÃO, 2019). Nosso interesse ancora-se na investigação do uso da linguagem em práticas sociais cotidianas, a partir da análise dos sentidos criados pelo discurso em interações sociais (EGGINS, 2004).

A seguir, discorremos sobre a fundamentação teórica acima mencionada e, posteriormente, apresentamos os caminhos metodológicos que adotamos para o desenvolvimento do estudo e da análise dos dados. Por fim, terminamos este artigo com os nossos entendimentos sobre a construção de crenças no contexto investigado.

\section{Crenças e ensino-aprendizagem de língua inglesa}

$\mathrm{O}$ interesse pelo estudo de crenças acerca do ensino-aprendizagem de línguas estrangeiras tem motivado, desde a década de 1980, inúmeras pesquisas em diferentes níveis e contextos educacionais (SILVA, 2007). No cenário brasileiro, no que tange ao ensinoaprendizagem de língua inglesa, podemos encontrar estudos sobre crenças voltados: à formação docente (BARCELOS, 2004); às formas de ensinar e aprender (BARCELOS, 2006; SILVA, 2006) no Ensino Fundamental I (ROCHA, 2010), no Ensino Fundamental II (SANTOS; FERMINO, 2013) e no Ensino Médio (SOUZA, 2016); aos professores e aos alunos de escolas públicas (COELHO, 2006); ao ensino-aprendizagem no contexto rural (LACERDA, 2014), dentre outros. Na área dos Estudos da Linguagem, na qual esta pesquisa se insere, entendemos que ainda existem poucos estudos sobre as crenças, a partir do olhar de crianças. Portanto, acreditamos poder contribuir para a área ao trazer as opiniões e as crenças dos três alunos acerca do professor de inglês, no contexto do primeiro segmento do Ensino Fundamental. 
Na pesquisa que compartilhamos neste artigo, entendemos que crenças relacionam-se à convicção de que algo é verdadeiro e que se baseiam em avaliações pessoais e subjetivas advindas de experiências anteriores. Compõem-se, logo, de "pressupostos que dão sentido ao mundo" (GIMENEZ, 2002 apud PERINE, 2012, p. 109), não sendo apenas um mero reflexo da realidade, já que são construídas na experiência, no percurso da interação com os demais integrantes desta realidade (PERINE, 2012). Nesse viés, as crenças são "sociais (mas também individuais), dinâmicas, contextuais e paradoxais", segundo Barcelos (2006, p. 18), ou seja, podem mudar com o tempo em diferentes contextos. Seguimos, assim, a definição de crenças como "uma forma de pensamento, construções da realidade, maneiras de ver e perceber o mundo e seus fenômenos, coconstruídas em nossas experiências resultantes de um processo interativo de interpretação e (re)significação" (BARCELOS, 2006, p. 18), por entendermos que o seu caráter social e interacional alinha-se à abordagem social de linguagem na qual nos inspiramos.

Alinhada a essa proposta social, Barcelos (2006, p. 19) ainda discorre que as crenças "não estão dentro de nossas mentes como uma estrutura mental pronta e fixa, mas mudam e se desenvolvem à medida que interagimos e modificamos nossas experiências e somos ao mesmo tempo modificados por elas". A esse respeito, as crenças construídas pelos alunos participantes deste estudo fazem sentido no contexto sócio-histórico-cultural no qual estão inseridos, levando-se em consideração a escolaridade e a idade de cada um. Desse modo, suas crenças são influenciadas pela família, pelos colegas e pela mídia, pelo material didático e pelas experiências pregressas com o idioma, e pelos "pressupostos que dão sustentação à compreensão que têm da língua e ao modo como examinam e modelam seu próprio processo de aprendizagem" (PERINE, 2012, p. 108).

Seguindo esse mesmo pensamento, Richards e Lockhart (2007, p. 52) discorrem sobre o sistema de crenças dos alunos que abrange "um amplo escopo de aspectos que podem influenciar sua motivação para aprender, suas expectativas em relação ao aprendizado da língua, suas percepções sobre o que é fácil ou difícil sobre a língua, bem como que tipos de estratégias de aprendizagem que preferem”. Os autores apontam que tópicos relacionados à natureza da língua a ser aprendida, à questão do falante nativo, aos objetivos para o ensinoaprendizagem de línguas, dentre outros, podem compor o sistema de crenças de um aluno.

Por fim, como também sugere Barcelos (2004, p. 148), uma investigação acerca das crenças dos alunos deve incluir: “(a) as experiências e ações desses alunos; (b) suas interpretações dessas experiências; (c) o contexto social e como ele molda as experiências dos alunos, e (d) como os alunos usam suas crenças para lidar com a tarefa complexa de aprender 
línguas". Isso posto, buscamos entender a construção das crenças dos alunos participantes acerca do que seria "um bom professor de inglês", e passamos, então, à apresentação da abordagem sociossemiótica de Halliday (1994), que busca entender a criação de sentidos de um texto e como esses materializam-se discursivamente a partir de escolhas léxicogramaticais que falantes/escritores e ouvinte/leitores fazem em diferentes interações sociais.

\section{Linguística Sistêmico-Funcional}

A Linguística Sistêmico-Funcional (doravante LSF) (HALLIDAY, 1994), em sua abordagem, propõe, ao mesmo tempo, uma teoria social e semiótica, uma gramática funcional. Tendo uma perspectiva de análise da linguagem em uso, observa como o significado é construído pela linguagem nas diferentes práticas sociais, partindo da sociedade e das situações de uso da língua para o estudo da linguagem. Além disso, em sua proposta, a LSF indica que os usuários da língua constroem seus significados com base em redes de sistemas linguísticos interdependentes, sendo que um sistema é "um conjunto de opções, disponíveis a falantes/escritores, que abarca significados que são tipicamente expressos em contextos particulares, e também as formas linguísticas necessárias para tal expressão" (MARTIN, 2001, p. 142). Segundo Halliday (HALLIDAY, 1970, p. 142 apud FUZER; CABRAL, 2014, p. 26), “o sistema de opções válidas é a gramática da língua, e o falante ou escritor seleciona desse sistema: não no vácuo, mas no contexto de situações de fala".

É a partir dos elementos da cultura que o falante/escritor seleciona o modo e a forma de produção do texto falado ou escrito. As atividades humanas são mediadas pela linguagem, o que requer de seus usuários uma grande experiência no que se refere ao reconhecimento, diferenciação e classificação dessas escolhas em situações diversas. Por conseguinte, o contexto assume papel fundamental na perspectiva sistêmico-funcional.

Na teoria de Halliday (1994), a linguagem é dividida em três estratos interconectados: grafo-fonológico, léxico-gramatical e semântico-discursivo, que são realizados tendo por base os contextos de cultura e de situação. O contexto de cultura é amplo e envolve o contexto histórico de uma comunidade, assim como a cultura dos seus participantes. O contexto de situação é dividido em três variáveis - campo, relações e modo (EGGINS, 2004; HALLIDAY; MATTHIESSEN, 2014), que apresentam uma relação sistemática e dialética com três metafunções, a saber: o campo é realizado na metafunção ideacional (quando usamos a linguagem para criar sentidos acerca de experiências relacionadas ao nosso mundo interior ou exterior); as relações na metafunção interpessoal (quando usamos a linguagem 
para estabelecer e manter relações sociais); e o modo na metafunção textual (que se debruça sobre a organização das nossas mensagens, relacionando-as a outras mensagens).

No caso desta pesquisa, trazemos um olhar analítico para metafunção interpessoal, com foco em seu sistema de avaliatividade. Tal escolha se justifica pela própria atividade pedagógica que trazemos em nossas análises, que buscou refletir com os alunos sobre o que é ser "um bom professor" de língua inglesa. Por certo, as interações discursivas voltaram-se à avaliação, trazendo valores morais e julgamentos para as conversas entre Mara e os participantes, seus alunos na escola onde leciona. Portanto, a avaliatividade torna-se o sistema de análise pertinente para a investigação dos momentos avaliativos que emergem no discurso dos alunos, assim como para a análise da contribuição dos recursos linguísticos avaliativos na construção das crenças sobre o professor de língua inglesa.

O sistema de avaliatividade (MARTIN; WHITE, 2005) pode ser entendido como "um sistema que engloba todo o potencial existente no sistema linguístico para procedermos a avaliações em nosso cotidiano" (VIAN JR., 2012, p. 119) e é um dos seis sistemas localizados no estrato da semântica do discurso, junto com a negociação (ambos no domínio semântico interpessoal), com a ideação e a conjunção (domínio semântico ideacional) e com a identificação e a periodização (domínio semântico textual). A avaliatividade é composta por três subsistemas: atitude (que lida com a linguagem das emoções, da ética e da estética), engajamento (que busca saber que vozes se encontram na avaliação) e gradação (que investiga a força e o foco conferidos aos momentos avaliativos).

Afeto, julgamento e apreciação são domínios que se sobrepõem e integram o subsistema da atitude ${ }^{1}$, que nos orientará para a análise dos dados. O afeto lida com as emoções de in/segurança, in/satisfação e in/felicidade; o julgamento com questões éticas, por meio de avaliações de estima social ou de sanção social, relacionadas ao comportamento humano; e a apreciação, que se refere à estética, ou seja, à composição, à reação e ao valor de objetos e fenômenos em geral. A atitude pode ser expressa de forma explícita ou implícita, positiva ou negativa, sendo sempre negociada entre falante/escritor e ouvinte/leitor durante a interação (MARTIN; WHITE, 2005).

Nesse viés, a avaliação é aqui entendida como um recurso interacional, tendo muitas faces e fases, apresentando interdependência com o contexto (ALBA-JUEZ; THOMPSON, 2014). Concebida como uma prática social, inclui "qualquer situação em que um falante

\footnotetext{
${ }^{1}$ Neste artigo, privilegiamos a apresentação dos domínios da atitude por esses lidarem com as avaliações de julgamento e afeto, categorias mais recorrentes no corpus analisado. Em Martin e White (2005), há a descrição detalhada dos subsistemas do Engajamento e da Gradação.
} 
indica o significado ou o valor social de uma pessoa, coisa, evento ou relação", podendo ser vista como uma parte importante da "dimensão moral da linguagem" (LINDE, 1997, p. 152153). É a partir das avaliações que fazemos das nossas vivências cotidianas que construímos crenças a respeito dos contextos nos quais nos inserimos e a forma como as avaliações são realizadas linguisticamente dependem de nossas escolhas léxico-gramaticais. Neste estudo, tais escolhas estão diretamente relacionadas às idades dos participantes, às suas vivências familiares e às experiências socioculturais de cada um, conforme veremos adiante, nas reflexões sobre as conversas entre Mara e seus alunos.

\section{Caminhos metodológicos e reflexões sobre os dados}

As escolhas epistemológicas que orientam esta investigação estão em consonância com os princípios éticos informados na Resolução n 510 (Conselho Nacional de Saúde, 2016) e a presente pesquisa possui parecer favorável emitido pela Câmara de Ética em Pesquisa da Pontifícia Universidade Católica do Rio de Janeiro (PUC-Rio). Com a finalidade de documentar tais cuidados éticos, antes de darmos início ao desenvolvimento da pesquisa, obtivemos a autorização assinada pelos responsáveis de cada criança e também o assentimento de cada uma delas, sendo uma de nossas ações a troca por nomes fictícios para proteger a identidade dos alunos participantes.

A presente pesquisa conjuga a busca das autoras por entendimentos sobre questões voltadas ao contexto pedagógico em seus ambientes de atuação acadêmica e profissional: Adriana, como docente em uma universidade na cidade do Rio de Janeiro, trabalhando com a formação de professores de línguas; Mara, como professora de língua inglesa, atuando na escolarização de crianças no ensino básico.

O paradigma qualitativo e interpretativo (DENZIN; LINCOLN, 2006) orienta o desenvolvimento do estudo realizado, a partir de dados gerados em 2018, por Mara, na escola onde trabalha como professora por quase duas décadas. A instituição pertence à rede particular de ensino do Estado do Rio de Janeiro e atende alunos da Educação Infantil ao Ensino Médio e, como atividade extracurricular, oferece aulas de língua inglesa em seu Programa Bilíngue - somente da Educação Infantil ao $5^{\mathrm{o}}$ ano do Ensino Fundamental.

Os dados aqui apresentados são um recorte de uma pesquisa mais ampla (GRIFFO, 2019) que envolveu diferentes interações entre Mara, dois alunos do $5^{\circ}$ ano e cinco alunos do $4^{\mathrm{O}}$ ano, que formavam uma turma do Programa Bilíngue, sob sua responsabilidade. O objetivo da investigação foi, então, construir entendimentos sobre as crenças e emoções do grupo, com 
base em desenhos, pequenos textos de diferentes gêneros discursivos, conversas e debates, além de anotações no diário de campo da professora.

Para este artigo, o corpus inclui dois desses momentos: atividades pedagógicas realizadas em inglês na sala de aula e, posteriormente, conversas individuais em português acerca das mesmas. Mais especificamente, a primeira proposta incluiu a elaboração de cinco perguntas para entrevistar um professor de inglês que, hipoteticamente, iria trabalhar na escola onde os alunos estudam. A segunda foi atribuir características a "um bom professor de inglês".

As conversas entre Mara e os alunos foram gravadas em áudio durante o horário das aulas. Em seguida, foram transcritas de acordo com as convenções sugeridas por Bastos e Biar $(2015)^{2}$. Nosso foco de análise do discurso oral recorre sobre os elementos paralinguísticos que corroboram a construção de avaliações na fala, tais como alongamentos de vogais, ênfases em palavras por aumento ou diminuição do tom da voz, dentre outros.

Nossas análises recaem sob o subsistema de atitude, "que se localiza no eixo das opiniões" (BALOCCO, 2010, p. 41), uma vez que nos interessa conhecer os posicionamentos dos alunos sobre "um bom professor de inglês". Em alinhamento com a proposta metodológica sugerida por Macken-Horarik e Isaac (2014) para a análise da atitude, primeiramente, realizamos a leitura dos dados gerados nas conversas com os sete alunos do grupo, fazendo marcações manuais dos momentos avaliativos. Posteriormente, detivemo-nos no tipo de avaliação realizada (afeto, julgamento e apreciação), quando logo observamos uma maior incidência de recursos avaliativos de afeto e de julgamento. Por fim, retornamos ao corpus com o intuito de ressaltar as avaliações que contribuíram para a construção das crenças dos alunos: (i) crenças sobre a personalidade e sobre os estados de humor do professor; (ii) sobre suas formas de ver o mundo; e (iii) sobre sua capacidade profissional. A título de recorte, trazemos as crenças de Giovana ( $5^{\circ}$ ano), Gael e Tito $\left(4^{\circ}\right.$ ano) que se voltam à capacidade profissional do suposto professor, conforme veremos na análise dos dados a seguir.

\footnotetext{
${ }^{2}$ Convenções de transcrição utilizadas: (.) descida leve sinalizando final de enunciado; (?) subida rápida sinalizando uma interrogação; (,) descida leve na entonação; (::) alongamento de som; (-) corte abrupto no enunciado; (palavra) ênfase em uma sílaba ou palavra; (..) pausa com menos de um segundo; $\left({ }^{\circ}\right.$ palavra $\left.{ }^{\circ}\right)$ volume baixo; ( $\uparrow$ ) entonação ascendente; $(\downarrow)$ entonação descendente; (hh) risadas, aspirações; ("palavra") diálogo construído; (>palavra<) fala mais rápida; ((comentário)) comentários do transcritor; (/.../) corte na transcrição.
} 
A interação abaixo, exposta neste primeiro fragmento da conversa de Giovana com sua professora, ocorre enquanto a aluna revisita as perguntas que escreveu para entrevistar um professor de inglês imaginário. Suas atividades encontravam-se em cima da mesa durante a conversa, com o intuito de provocar reflexões e de facilitar eventuais consultas. Na sequência aqui apresentada, Mara indaga sobre a relevância das perguntas elaboradas pela aluna. Nesse momento, Giovana se mostra disposta a analisar, de forma reflexiva, sua própria atividade.

\section{Fragmento 1.1}

\begin{tabular}{|c|c|c|}
\hline 21 & Giovana & do you work in another school? \\
\hline 22 & Mara & por que você acha que é importante essa pergunta? \\
\hline $\begin{array}{l}23 \\
24 \\
25 \\
26\end{array}$ & Giovana & $\begin{array}{l}\text { porque se a pessoa já tivesse trabalhado ou } \\
\text { trabalha em outra escola além dessa seria um } \\
\text { horário <diferente> por exemplo é: e também ela já } \\
\text { teria: <alquma>experiência né } \uparrow\end{array}$ \\
\hline 27 & Mara & aham em outra escola né \\
\hline 28 & Giovana & [em outra escola] \\
\hline 29 & Mara & qual a outra pergunta que você fez? \\
\hline 30 & Giovana & ah vamos ver do you have experience with children? \\
\hline 31 & Mara & isso é importante? \\
\hline $\begin{array}{l}32 \\
33 \\
34\end{array}$ & Giovana & $\begin{array}{l}\text { isso é importante imagina se a pessoa não tem } \\
\text { nenhuma experiência com a criança né } \uparrow \text { <isso seria> } \\
\text { um: problema((risos)) }\end{array}$ \\
\hline
\end{tabular}

Podemos observar que as falas da aluna, nesse momento da interação, fazem referência direta à questão da experiência que um professor deve ter para que seja considerado um bom docente. A escolha repetitiva do léxico "experiência", nas linhas 26 e 33, ilustra a carga semântica das avaliações de julgamento positivo de estima social que constroem a crença de que um bom professor deve ser experiente. Além disso, os itens modais "alguma" (linha 26) e "nenhuma" (linha 33) contribuem para a sua avaliação, uma vez que a ausência de experiência com crianças constituir-se-ia em um problema (linha 34). Mara corrobora a construção da avaliação de julgamento do professor ao se certificar se as perguntas da aluna continham aspectos realmente importantes (linhas 22 e 31). Giovana, assim, esclarece que a experiência com crianças é importante e que a falta desta seria um problema para ela. Como pode um professor que trabalha na escola não ter experiência com crianças? - questionamento levantado por ela ao usar a fala hipotética "imagina se a pessoa" (linha 32) como um recurso para enfatizar o problema e, dessa forma, conferir força à sua avaliação e às suas crenças construídas a partir desta. 
Observamos que Giovana realiza um julgamento de estima social, no nível da capacidade, que ilustra sua crítica explícita ao professor que "não tem nenhuma experiência com a criança" (linhas 32-33). Por ser o julgamento uma institucionalização do sentimento no comportamento humano (MARTIN, 2001), podemos inferir que Giovana também elabora suas crenças a partir de avaliações implícitas de afeto, uma vez que sua satisfação como aluna parece levar em conta a experiência do professor. Nesse sentido, ela ilustra suas crenças de que um bom professor deve ter experiências prévias para que possa ser qualificado a dar aulas para crianças no ambiente pedagógico com o qual a aluna está familiarizada, indo ao encontro do proposto por Barcelos (2004): o contexto social e as experiências dos alunos moldam suas crenças. Tal fato faz-se presente na continuação da conversa, como veremos a seguir.

\section{Fragmento 1.2}

\begin{tabular}{|c|c|c|}
\hline 35 & Mara & e qual outra pergunta você fez? \\
\hline 36 & Giovana & mmm vamos ver did you live in another country? \\
\hline 37 & Mara & então por que você fez essa pergunta? \\
\hline $\begin{array}{l}38 \\
39 \\
40 \\
41\end{array}$ & Giovana & $\begin{array}{l}\text { porque a pessoa né poderia saber outra língua isso } \\
\text { seria muito interessante teria é: : saberia por } \\
\text { exemplo o: : como é: o como é o outro lugar teria } \\
\text { tido né } \uparrow \text { a experiência de um lugar diferente }\end{array}$ \\
\hline 42 & Mara & ${ }^{\circ}$ hum ${ }^{\circ}$ e você colocou mais uma pergunta qual foi? \\
\hline 43 & Giovana & how many years do you have ((risos)) \\
\hline 44 & Mara & ${ }^{\circ}$ não ${ }^{\circ}$ how many years $=$ \\
\hline 45 & Giovana & [how many years did you study english?] \\
\hline 46 & Mara & isso é importante? \\
\hline $\begin{array}{l}47 \\
48\end{array}$ & Giovana & $\begin{array}{l}\text { sim porque né tem um certo tempo né que você } \\
\text { deveria estudar inglês ((risos)) }\end{array}$ \\
\hline 49 & Mara & quanto tempo que você acha que a pessoa deveri= \\
\hline 50 & Giovana & [uns dez anos] \\
\hline
\end{tabular}

Giovana, então, lê outra pergunta em sua lista "did you live in another country” (linha 36) e justifica sua escolha dizendo que a pessoa/professora "poderia saber outra língua isso seria muito interessante [...] a experiência de um lugar diferente" (linhas 38-41). Mais uma vez, há a construção de sua avaliação de julgamento positivo de estima social, no nível da capacidade, quando a escolha pelo adjunto "muito" aumenta a força avaliativa do atributo "interessante", indicando sua crença de que o professor deve ter vivências em outros países durante sua formação acadêmica e profissional. A crença bastante perpetuada de que “aprender a falar inglês é 'lá fora' e nunca na escola" (ARAGÃO, 2019, p. 253) parece ser, assim, compartilhada por Giovana. 
Por fim, observamos que o uso de "experiência", repetido por Giovana algumas vezes ao longo da conversa, ilustra em seu discurso suas crenças de que o bom professor de inglês deveria ter experiências prévias (i) em ambiente profissional, (ii) na relação com as crianças e (iii) uma certa proficiência linguística, a qual Giovana reforça ao dizer que uma professora

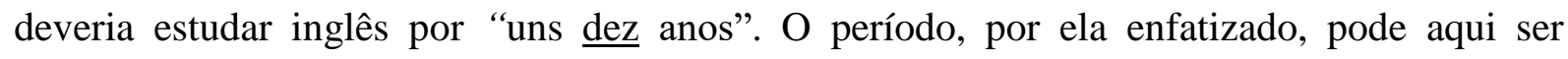
considerado como um elemento de forte reforço em sua avaliação de julgamento e de afeto de satisfação, este institucionalizado no julgamento de estima social, uma vez que corresponde à sua própria idade. Pelas suas perguntas para entrevistar um professor de inglês, Giovana deixa transparecer discursivamente suas crenças.

A importância da experiência também é trazida por Gael em sua interação com Mara, como veremos no fragmento 2. Contudo, de forma diferente de Giovana, o aluno enfatiza a experiência de um bom professor a partir de seu conhecimento e de seu domínio da língua, ao se referir à mesma atividade de entrevista.

\section{As conversas sobre o professor de inglês: o domínio da língua}

\section{Fragmento 2}

\begin{tabular}{|c|c|c|}
\hline $\begin{array}{l}127 \\
128\end{array}$ & ara & $\begin{array}{l}\text { você perguntou assim se ela fala inglês bem o que } \\
\text { é falar inglês bem? o que vo= }\end{array}$ \\
\hline $\begin{array}{l}129 \\
130 \\
131 \\
132 \\
133 \\
134 \\
135 \\
136 \\
137 \\
138 \\
139\end{array}$ & Gael & 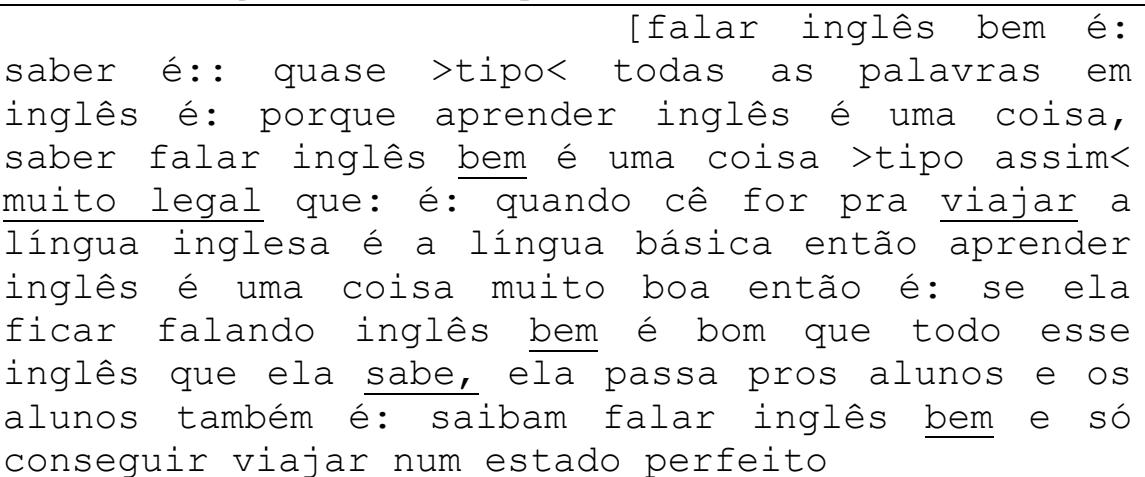 \\
\hline
\end{tabular}

Gael responde à indagação feita por Mara (linhas 127-128) esclarecendo que uma boa professora de inglês tem que "falar inglês bem" (linha 130) e "saber é:: quase >tipo< todas as palavras em inglês" (linhas 131-132). Apesar da graduação da carga semântica contida no adjunto "quase", o aluno enfatiza que a professora deve saber aproximadamente todas as palavras da língua. Assim, sua avaliação é construída a partir de um julgamento positivo de estima social, focalizado na capacidade de uma boa professora de ter um profundo conhecimento do léxico da língua que leciona. 
Nesse segundo fragmento, notamos que há a presença de diferentes processos ${ }^{3}$, os quais definem a capacidade intelectual de uma boa professora. As escolhas empregadas por Gael do processo verbal "falar" (linha 129) e do mental cognitivo "saber" (linha 130) nos levam a interpretar que ele prioriza o conhecimento linguístico em detrimento de questões interacionais no contexto escolar. As perguntas que faria para a professora supostamente entrevistada ("you speak very well?" e "you are a very good teacher you want to be hired?") são trazidas para a conversa pela professora, nas linhas 127-128: "você perguntou assim se ela fala inglês bem o que é falar inglês bem?". Gael constrói sua resposta avaliando as qualidades de uma boa professora com base em julgamentos positivos de estima social, apontando para o fato de que um professor de inglês deve ter conhecimento da língua (“saber”) e ser capaz de comunicar-se com fluência ("saber falar"). Com posicionamento avaliativo, o aluno expressa sua crença, também bastante difundida, de que "falar bem é falar igual a um falante nativo" (ARAGÃO, 2019, p. 253).

Em seguida, o aluno explica que "saber falar inglês bem é uma coisa >tipo assim< muito legal" (linhas 132-133). Gael apresenta, em seu julgamento, uma crença que define um professor de inglês positivamente, voltada ao domínio da língua: para ser um bom professor, não basta apenas saber falar, mas falar "bem", enfatizado em sua fala. Sua crença ainda refere-se à fluência verbal, à habilidade de falar e de compreender o idioma nas interações entre pessoas, a qual julga positivamente com a escolha de "muito legal", lançando mão do recurso paralinguístico de ênfase no atributo "legal", reforçado pela escolha de "muito", conferindo força à sua avaliação.

Por duas vezes, Gael faz uso do processo material de movimento "viajar", nas linhas 133-134, "quando cê for pra viajar a língua inglesa é a língua básica” e, nas linhas 138-139, "conseguir viajar num estado perfeito". Desse modo, avalia, em uma apreciação, o valor e a importância da língua inglesa e indica suas crenças acerca do inglês como língua franca ("língua básica", linha 134). O fato de associar o aprendizado da língua inglesa a viagens parece revelar suas próprias experiências familiares e vivências socioculturais, exemplificando a relação de interdependência entre crenças e contexto (BARCELOS, 2004, 2006; PERINE, 2012). De acordo com esse fragmento, é possível inferir que "viajar num

\footnotetext{
${ }^{3}$ Segundo Fuzer e Cabral (2014), na gramática sistêmico-funcional, em seu sistema de transitividade, há a classificação de três tipos principais de processos: materiais (ligados às representações das experiências externas), mentais (ligados às representações das experiências internas) e os relacionais (ligados às representações das relações). Três outros tipos de processos, os secundários, encontram-se na fronteira com os principais: comportamentais (ligados às representações dos comportamentos humanos), verbais (ligados às representações dos dizeres) e os existenciais (ligados às representações da existência de um participante). Para uma leitura mais detalhada, conferir Halliday; Matthiessen (2014, p. 213-220).
} 
estado perfeito" (linha 139) elabora um julgamento positivo que nos remete à habilidade de comunicar-se, fazendo uso da língua em interações durante as viagens. Lembrando que, segundo Gael, tal habilidade é atribuída à capacidade do professor de transmitir seu inglês para os alunos no contexto escolar. Mais uma vez, notamos a construção de crenças, dessa vez relacionadas ao fato de que é o professor quem ensina, quem "passa pros alunos" (linha 137).

Da mesma maneira que Giovana e Gael, Tito, no terceiro e último fragmento, expressa suas crenças a partir das avaliações que faz acerca de um bom professor de inglês. Como discutiremos, a seguir, a questão da influência do professor para a formação futura de seus alunos é premente para Tito.

As conversas sobre o professor de inglês: a importância do lúdico para a formação futura

\section{Fragmento 3}

\begin{tabular}{|c|c|c|}
\hline $\begin{array}{l}103 \\
104 \\
105\end{array}$ & Mara & $\begin{array}{l}\text { uma outra coisa que eu ia te perguntar é que } \\
\text { uma vez você falou que um professor de inglês } \\
\text { tem que ser <inteligente> e <engraçado> }\end{array}$ \\
\hline $\begin{array}{l}106 \\
107\end{array}$ & Tito & $\begin{array}{l}\text { [não é necessariamente que tem que ser] mas } \\
\text { se for... é uma coisa muito legal }\end{array}$ \\
\hline 108 & Mara & por quê? \\
\hline $\begin{array}{l}109 \\
110 \\
111 \\
112 \\
113 \\
114\end{array}$ & Tito & $\begin{array}{l}\text { porque os professores têm que fazer o trabalho } \\
\text { o trabalho é ensinar a gente e nos preparar pra } \\
\text { faculdade essas coisas eles fazem seu trabalho } \\
\text { sim ma:s seria muito mais divertido aprender } \\
\text { com eles ao mesmo tempo que eles brincassem com } \\
\text { a gente coisas diferentes pra eles }\end{array}$ \\
\hline
\end{tabular}

No fragmento, Mara solicita que Tito comente sua segunda atividade, quando descreve um bom professor de inglês como inteligente e engraçado (linha 105). Sua avaliação recorre a um julgamento de estima social positivo e podemos observar a institucionalização do afeto de satisfação nesse julgamento, pois, para nós, o que Tito quer dizer é que ele gosta de professores inteligentes e engraçados. O aluno mostra que esses dois adjetivos juntos podem ocorrer ou não em relação à figura do professor, não havendo a necessidade absoluta dessa combinação, a qual ele deixa marcado pelos adjuntos modais "não", "necessariamente" e "tem que", (linha 106). Em seguida, indica uma oposição de ideias com sua escolha "mas se for... é uma coisa muito legal" (linhas 106-107), o que nos leva a interpretar que um professor inteligente e engraçado é avaliado como algo positivo e desejado pelo aluno. O uso do intensificador "muito", acrescido do recurso paralinguístico de ênfase, reforça o fato de que os dois atributos juntos são positivos. 
Na sequência, a pergunta "por quê?” (linha 108) dá a chance para o aluno elaborar melhor o seu pensamento, explicando que "os professores têm que fazer o trabalho o trabalho é ensinar a gente e nos preparar pra faculdade" (linhas 109-111). De acordo com Tito, "eles fazem seu trabalho sim" (linha 111), que seria a meta a que se almeja chegar em termos educacionais. O uso do processo relacional "é" indica que, para o aluno, este é o trabalho do professor e não outro qualquer, e sua escolha pelo adjunto "sim" reforça essa crença. Há, então, uma delimitação da função do professor que pode ser entendida como essencial para ele. Essa visão ilustra uma crença de que a escola é a passagem para a universidade ou de que a escola serve como porta de entrada para o ensino superior, uma vez que seu papel é "preparar" os alunos para o seu ingresso no ensino superior. Ao fazer essas escolhas, Tito gera avaliações de julgamento positivo de estima social. Apesar de revelar suas crenças já cristalizadas do ensino como ascensão social, para uma criança de 9/10 anos de idade, a universidade deveria ainda ser algo distante e vago, o que nos leva a interpretar que tais crenças foram social e culturalmente construídas, nos contextos vivenciados por ele, como, por exemplo, o familiar.

Em seguida, faz uma oposição marcada pela conjunção "ma:s", lançando mão dos recursos paralinguísticos avaliativos de alongamento de vogal e de ênfase para apresentar duas ideias, as quais, em nossa leitura, são contrastantes: professor-obrigação-trabalho, aluno-

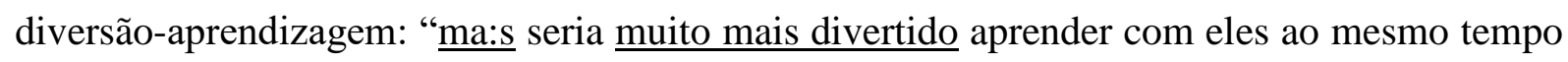
que eles brincassem com a gente" (linhas 112-114). Uma noção de simultaneidade é expressa na escolha de "ao mesmo tempo", a qual parece indicar que os professores deveriam brincar sem deixar de lado a função de ensinar. Percebemos, nesse trecho, uma avaliação de afeto de satisfação voltada ao fato hipotético, uma vez que um bom professor "seria" aquele que prepararia o aluno para o seu futuro, ensinando de forma mais lúdica, abarcando ambos os desejos do aluno em relação ao seu professor.

Por fim, ressaltamos que suas escolhas léxico-gramaticais ilustram a crença, talvez mais infantil, de que aprender tem que ser divertido, o que pode estar em oposição a uma crença mais adulta de que a escola deve preparar o aluno para a universidade. Entendemos que Tito reproduz, nessa visão, crenças socialmente construídas de que a tarefa do professor é ensinar enquanto a dos alunos é aprender se divertindo.

\section{Considerações finais}

Ao apresentar seus entendimentos sobre quem é ou deveria ser um bom professor de 
inglês, os alunos participantes construíram crenças a partir de suas experiências dentro do ambiente escolar. Partindo da concepção de que crenças são dinâmicas e mutáveis (BARCELOS, 2004; 2006), é possível apontar que, no momento em que este estudo foi realizado, o professor de inglês deveria: ter experiências profissionais e vivências em outros países; falar inglês bem; brincar e ensinar ao mesmo tempo. Faz-se importante ressaltar a idade, o nível de escolarização e os aspectos sociais e culturais vivenciados individualmente por cada aluno. Certamente, são aspectos que exercem influência direta sobre suas avaliações e suas crenças, as quais podem ter sofrido mudanças desde a elaboração deste artigo.

Entendemos que as crenças que emergiram nas falas de Giovana, Gael e Tito foram construídas a partir de suas avaliações de julgamento e de afeto que, primordialmente, voltaram-se à estima social positiva de um bom professor, bem como à satisfação dos próprios alunos. Negociadas ao longo das interações, tais avaliações, assim como as crenças, foram fundamentadas na inter-relação entre suas experiências individuais e coletivas.

Retomando o pensamento de Barcelos (2004), exposto anteriormente, uma pesquisa sobre crenças deve levar em conta reflexões sobre as ações dos alunos na complexa tarefa de aprender línguas. Ao tecer interpretações sobre o contexto educacional no qual se encontravam inseridos, os três participantes deste estudo trouxeram à tona as seguintes crenças: (i) a importância da experiência do professor; (ii) o seu domínio da língua inglesa; e (iii) o seu foco na formação futura do aluno. Podemos dizer que essas crenças são perpetuadas pelos alunos tomando por base, em um senso comum, o que seja relevante no ensinoaprendizagem de língua inglesa (RICHARDS; LOCKHARD, 2007). A partir de suas avaliações e seus posicionamentos em relação ao processo de ensino-aprendizagem, entendemos o que seja/seria "um bom professor de inglês". É interessante observar que crenças compartilhadas por professores (BARCELOS, 2004) e alunos mais velhos (SOUZA, 2016), acerca do ensino de língua inglesa, também integram o discurso de Giovana, Gael e Tito, crianças entre 9 e 10 anos de idade. Tal aspecto parece corroborar o fato de que seus contextos históricos e socioculturais exercem grande influência na forma como entendem o mundo e expressam seus afetos e julgamentos de valor acerca deste.

Por fim, esperamos que esta pesquisa possa contribuir para a área de ensinoaprendizagem de língua inglesa para crianças, especialmente no que diz respeito às suas crenças sobre o ambiente escolar. Acreditamos que, assim, o presente estudo permite ampliar reflexões sobre o tema, ao evidenciar a importância da investigação das crenças de jovens estudantes, que até o presente momento, parece insipiente no cenário educacional brasileiro. 


\section{REFERÊNCIAS}

ARAGÃO, Rodrigo C. Linguajar e emocionar os tempos de crise na formação de professores de línguas. In: SILVA, Walkyri M.; SILVA, Wagner R.; CAMPOS, Diego M. (Orgs.).

Desafios da formação de professores na linguística aplicada. Campinas, SP: Pontes Editores, 2019. p. 243-276.

BALOCCO, Anna E. O sistema do engajamento aplicado a espaços opinativos na mídia escrita. In: VIAN JR., Orlando; SOUZA, Anderson A.; ALMEIDA, Fabíola A. S. D. P. (Orgs.). A linguagem da avaliação em língua portuguesa: estudos sistêmico-funcionais com base no Sistema de Avaliatividade. São Carlos: Pedro \& João Editores, 2010. p. 41-55.

BARCELOS, Ana M. F. Crenças sobre aprendizagem de línguas, Linguística Aplicada e ensino de línguas. Linguagem \& Ensino, Pelotas, v. 7, n. 1, p. 123-156, 2004.

BARCELOS, Ana M. F. Cognição de professores e alunos: tendências recentes na pesquisa de crenças sobre ensino e aprendizagem de línguas. In: BARCELOS, Ana M. F.; ABRAHÃO, Maria Helena V. (Orgs). Crenças e ensino de línguas: foco no professor, no aluno e na formação de professores. Campinas, SP: Pontes, 2006. p. 15-42.

BARCELOS, Ana M. F. Desvendando a relação entre crenças sobre ensino e aprendizagem de línguas, emoções e identidades. In: GERHARDT, A. F. L.; AMORIM. M. A.;

CARVALHO, A. M. (Orgs). Linguística Aplicada e Ensino: Língua e Literatura. Campinas: Pontes, 2013. p. 153-186.

BASTOS, Liliana Cabral; BIAR, Liana de Andrade. Análise de narrativa e práticas de entendimento da vida social. D.E.L.T.A., São Paulo, v. 31, n. spe, p. 97-126, ago. 2015.

COELHO, Hilda S. H. “É possível aprender inglês na escola?” Crenças de professores sobre o ensino de inglês em escolas públicas. In: BARCELOS, Ana M. F.; VIEIRA ABRAHÃO, Maria Helena (Orgs.). Crenças e ensino de línguas: foco no professor, no aluno e na formação de professores. Campinas, SP: Pontes Editores, 2006. p. 125-143.

CONSELHO NACIONAL DE SAÚDE. 2016. Resolução $n^{\circ}$ 510. Disponível em: http://conselho.saude.gov.br/resolucoes/2016/Reso510.pdf. Acesso em: 03 abr. 2021.

DENZIN, Norman K.; LINCOLN, Yvonna S. O planejamento da pesquisa qualitativa: teorias e abordagens. 2. ed. Porto Alegre: Artmed, 2006.

EGGINS, Susan. An Introduction to Systemic Functional Linguistics. London: Continuum, 2004.

FUZER, Cristiane; CABRAL, Sara. Introdução à Gramática Sistêmico-Funcional em Língua Portuguesa. São Paulo: Mercado das Letras, 2014.

GRIFFO, Mara R. A. Praticante exploratórios aprendendo a viver juntos na escola. 2019. 193 f. Dissertação (Mestrado em Letras) - Pontifícia Universidade Católica do Rio de Janeiro - PUC-Rio, Rio de Janeiro, 2019.

HALLIDAY, Michael A. K. An Introduction to Functional Grammar. $2^{\text {nd }}$ ed. London: Arnold, 1994. 
HALLIDAY, Michael A. K.; MATHIESSEN, Christian. An Introduction to Functional Grammar. $4^{\text {th }}$ ed. London, New York: Arnold, 2014.

LACERDA, Ingrid S. Estudo de crenças no ensino-aprendizagem de língua estrangeira em contexto rural. 2014. $49 \mathrm{f}$. Trabalho de Conclusão de Curso (Licenciatura em Letras Português-Inglês) - Universidade Tecnológica Federal do Paraná, Curitiba, 2014.

LINDE, Charlotte. Evaluation as linguistic structure and social practice. In: GUNNARSSON, B. L.; LINELL P.; NORDBERG B. (Eds.). The Construction of Professional Discourse. London: Longman, 1997. p. 151-172.

MACKEN-HORARIK, Mary; ISAAC, Anne. Appraising Appraisal. In: THOMPSON, Geoff; ALBA-JUEZ, Alba (Eds.). Evaluation in Context. Amsterdam/Philadelphia: John Benjamins, 2014. p.67-92.

MARTIN, Jim R. Beyond Exchange: appraisal systems in English. In: HUSTON, Susan; THOMPSON, Geoff (Eds.). Evaluation in text: Authorial Stance and the Construction of Discourse. Oxford: Oxford University Press, 2001. p. 142-175.

MARTIN, Jim R.; WHITE, Peter R. R. The language of evaluation: appraisal in English. New York: Palgrave Macmillan, 2005.

MILLER, Inés K.; BARRETO, Beatriz. C.; NÓBREGA-KUSCHNIR, Adriana N. A.; SETTE, M. L.; BEZERRA, Isabel. C.; CUNHA, Maria I. A.; BRAGA, Walewska G. Prática Exploratória: questões e desafios. In: GIL, G.; ABRAHÃO, M. H. (Org.). Educação de professores de línguas: os desafios do formador. Campinas, SP: Editora Pontes, 2008. p. 145165.

MILLER, Inés K.; CUNHA, Maria Isabel; MORAES BEZERRA, Maria Isabel; NÓBREGA, Adriana N.; EWALD, Clarissa; BRAGA, Walewska G. Teaching English to Young Learners: Some Reflective Voices from Latin America. In: GARTON, Sue; COPLAND, Fiona. The Routledge Handbook of Teaching English to Young Learners. Abingdon: Routledge, 2019. p. 508-522.

PERINE, Cristiane M. A interface entre crenças, motivação, autonomia e o professor de línguas em formação. Revista Contemporânea de Educação, Rio de Janeiro, v. 7, n. 13, p. 107-127, 2012.

RICHARDS, Jack C.; LOCKHART, Charles. Reflective teaching in second language classrooms. Cambridge: Cambridge University Press, 2007.

ROCHA, Claudia H. Um estudo exploratório sobre o ensino de inglês no fundamental I: foco nas crenças dos participantes. In: SILVA, K. A. (Org.) Crenças, discursos e linguagem. Vol. I. Campinas, SP: Pontes Editores, 2010. p. 227-265.

SANTOS, Caroline da S.; FERMINO, Meryellen A. Ensino-aprendizagem de língua inglesa no ensino fundamental: um estudo de crenças. 2013. 65 f. Trabalho de Conclusão de Curso (Licenciatura em Letras Português - Inglês) - Universidade Tecnológica Federal do Paraná, Curitiba, 2013.

SILVA, Kleber A. O futuro do professor de língua inglesa no espelho: crenças e aglomerados de crenças na formação inicial. In: BARCELOS, Ana Maria Ferreira; ABRAHÃO, Maria 
Helena Vieira (Orgs). Crenças e ensino de línguas: foco no professor, no aluno e na formação de professores. Campinas, SP: Pontes, 2006. p. 105-124.

SILVA, Kleber A. Crenças sobre o ensino e aprendizagem de línguas na Linguística Aplicada: um panorama histórico dos estudos realizados no contexto brasileiro. Linguagem \& Ensino, Pelotas, v. 10, n. 1, p. 235-271, jan./jun. 2007.

SOUZA, Monica C. M. Avaliações e crenças em uma sala de aula de inglês para fins específicos sob o prisma sociocultural e sociossemiótico. 2016. 279 f. Tese (Doutorado em Estudos da Linguagem). Pontifícia Universidade Católica do Rio de Janeiro - PUC-Rio, Rio de Janeiro, 2016.

VELHO, Gilberto. Observando o familiar. In: NUNES, E. A aventura sociológica. Rio de Janeiro: Zahar, 1978. p. 123-132.

VIAN JR., Orlando. Avaliatividade, engajamento e valoração. D.E.L.T.A, São Paulo, v. 28, n. 1, p. 105-128, 2012. 